\title{
Relationship between progression of brain white matter changes and late-life depression: 3-year results from the LADIS study
}

Michael J. Firbank, Andrew Teodorczuk, Wiesje M. van der Flier, Alida A. Gouw, Anders Wallin, Timo Erkinjuntti, Domenico Inzitari, Lars-Olof Wahlund, Leonardo Pantoni, Anna Poggesi, Giovanni Pracucci, Peter Langhorne and John T. O'Brien on behalf of the LADIS group

\section{Background}

Brain white matter changes (WMC) and depressive symptoms are linked, but the directionality of this association remains unclear.

\section{Aims}

To investigate the relationship between baseline and incident depression and progression of white matter changes.

\section{Method}

In a longitudinal multicentre pan-European study (Leukoaraiosis and Disability in the elderly, LADIS), participants aged over 64 underwent baseline magnetic resonance imaging (MRI) and clinical assessments. Repeat scans were obtained at 3 years. Depressive outcomes were assessed in terms of depressive episodes and the Geriatric Depression scale (GDS). Progression of WMC was measured using the modified Rotterdam Progression scale.

\section{Results}

Progression of WMC was significantly associated with incident depression during year 3 of the study $(P=0.002)$ and remained significant after controlling for transition to disability, baseline WMC and baseline history of depression. There was no significant association between progression of WMC and GDS score, and no significant relationship between progression of WMC and history of depression at baseline.

\section{Conclusions}

Our results support the vascular depression hypothesis and implicate WMC as causal in the pathogenesis of late-life depression.

\section{Declaration of interest}

A.W. is a member of advisory boards for Lundbeck and ADAD-IJ, and has received honoraria from Pfizer, Lundbeck, Novartis and Philips. D.I. served on a scientific advisory board for Servier, and has received speaker honoraria from Bayer Schering Pharma, Novartis, Pfizer and Sanofi-Aventis. L.P. has received travel funds from Bayer Italy. J.T.O'B. has been a consultant for GE Healthcare, Servier and Bayer Healthcare and has received honoraria for talks from Pfizer, GE Healthcare, Eisai, Shire, Lundbeck, Lilly and Novartis.
Converging evidence implicates cerebral white matter changes (WMC) in the pathogenesis of late-life depression. Overall progression of WMC has been associated with cardiovascular risk factors, in particular hypertension and smoking, ${ }^{1-3}$ and in older people WMC severity is strongly associated with poorer response to treatment, development of future depressive symptoms and worse long-term outcome. ${ }^{4-12}$ Despite these findings, the direction of causation between WMC and depression remains unclear as most studies are cross-sectional; in particular, few studies have investigated the influence of WMC progression on depressive outcomes. The possibility still remains that both WMC and depressive symptoms are manifestations of a common pathological pathway, or that depressive symptoms pre-date development of WMC, as they do cardiovascular disease and stroke. ${ }^{13}$ The Prospective Study of Pravastatin in the Elderly at Risk (PROSPER) ${ }^{14}$ (of people aged 70 years and over, randomised to statins) found no association between progression of WMC andeither baseline or incident depressive features, although their level of baseline WMC were quite low (mean $2 \mathrm{ml}$ ). In contrast, the $3 \mathrm{C}$-Dijon study ${ }^{7}$ (a population-based study of community dwelling participants aged 65 years and over) demonstrated that baseline depression was predictive of WMC progression. Further prospective studies are required to answer this important question about directionality, which has major implications both for understanding the aetiology of depression and for informing appropriate management.

The LADIS (Leukoaraiosis and Disability in the elderly) study is a large multicentre pan-European longitudinal study of initially non-disabled older individuals that was established to investigate the relationship between WMC on magnetic resonance imaging (MRI) and subsequent development of disability, cognitive impairment and depression. We have previously reported on positive associations between baseline WMC and depressive symptoms in this sample. ${ }^{6,8,15}$ In this report we examine the relationship between depression at baseline and progression of WMC over 3 years, and the relationship between WMC progression and the development of future depressive symptoms and new depressive episodes. In line with the vascular depression hypothesis (that vascular disease changes to the brain predispose individuals to the development of depression by disrupting fibre tracts), we hypothesised that progression of WMC would be associated with the development of depressive symptoms, and we did not anticipate a relationship between depression at baseline and WMC progression. Since we hypothesised that the progression of WMC would precede depressive symptoms, our primary outcome was depression during year 3 . However, we also looked at the relationship of WMC progression to depression at any point during the 3 -year follow-up.

\section{Method}

\section{Sample}

Details of the LADIS study have been previously reported. ${ }^{8,16}$ In brief, 639 participants were recruited from the 11 European centres participating in the LADIS study (Amsterdam, 
Copenhagen, Florence, Graz, Göteborg, Helsinki, Huddinge, Lisbon, Mannheim, Newcastle upon Tyne and Paris). At entry participants were included if they were: (a) aged between 65 and 84; (b) living in the community; (c) non-disabled as assessed by the Instrumental Activities of Daily Living (IADL) scale (no impairment at all or only one item compromised) $;^{17}$ (d) accompanied by an informant; and (e) found to have any degree of age-related WMC on MRI scan, according to the Fazekas scale. ${ }^{18}$ Most participants $(n=460)$ were identified at neurology/ psychiatry clinics, and were discovered to have WMC during their investigation. The remainder were volunteers from other studies, or those with incidental findings of WMC on MRI or computed tomography. Participants were excluded if they had: (a) the presence of severe physical illnesses; (b) severe unrelated neurological diseases; (c) leukoencephalopathies revealed by brain imaging that turned out to be of non-vascular origin; or (d) severe psychiatric disorders. All procedures were explained to participants who gave written consent to participate.

As part of the study, all participants had a baseline MRI scan at their respective centres. The study design was to repeat MRI on all participants after 3 years. However, MRI scans were not repeated at one centre $(n=60)$ due to logistical constraints, leaving 579 possible participants in the study. Repeat magnetic resonance data were obtained from 394 individuals. Of the remaining 185, 38 had died, 63 had dropped out of the LADIS study altogether, 5 had unsatisfactory or missing baseline scans and 79 LADIS participants refused or were not available for a second scan. The mean interval between scans was 3.12 years (s.d. $=0.33$ ).

\section{MRI acquisition}

All centres used MRI systems with a field strength of $1.5 \mathrm{~T}$, apart from one centre that had a $0.5 \mathrm{~T}$ system. The standard protocol used for baseline scans ${ }^{16}$ was repeated. For the white matter rating, a FLAIR (fluid attenuated inversion recovery) sequence was acquired with the following parameters: field of view $(\mathrm{FOV})=250 \mathrm{~mm}, 256 \times 256$ or $256 \times 192$ matrix, $5 \mathrm{~mm}$ slice thickness, $0.5 \mathrm{~mm}$ slice gap, 19-28 slices, echo time (TE) $=100$ $140 \mathrm{~ms}$, repetition time $(\mathrm{TR})=6000-10000 \mathrm{~ms}$, inversion time $(\mathrm{TI})=2000-2500 \mathrm{~ms}$, echoes per shot 7-24. Volumetric analysis was performed by a single rater in Amsterdam on a Sparc 5 workstation on Unix (SUN, Palo Alto, California, USA). No distinction was made between subcortical and periventricular WMC. Areas of WMC around infarcts and lacunes were disregarded. Further details of the quantification process are described elsewhere. ${ }^{19}$

Progression of WMC was measured at one centre (Amsterdam) using the modified Rotterdam Progression scale (absence/presence of progression in nine brain regions). ${ }^{20}$ Areas of WMC around infarcts and lacunes were disregarded. We used the total sum of changes in all regions in order to increase sensitivity - previous research has shown that cardiovascular risk factors are associated with progression of total WMC. ${ }^{1-3}$

\section{Assessment of depressive outcomes}

Depressive symptoms were assessed by the self-completed 15-item Geriatric Depression Scale (GDS). ${ }^{21}$ The GDS is a self-reported questionnaire specifically developed as a screening instrument for the presence of depressive symptoms in older populations. ${ }^{21}$ Depressive symptoms were assessed at baseline as well as at 3 years. A history of treatment for depression was recorded at baseline, along with the date of any incident depression over the follow-up period. History of depression was defined as a past medical history for a depressive episode requiring treatment (i.e. prescription of antidepressant medication, psychotherapy, electroconvulsive therapy) or hospital admission. Incident depression at each yearly visit was similarly defined as any depressive episode requiring treatment or hospital admission in the year preceding the visit. Our primary outcome variable was a depressive episode in the year preceding the third follow-up visit. Both history and incident depression were obtained through a combination of participant interview and evaluation of the case notes.

\section{Assessment of potential mediators or confounders}

All participants had a comprehensive baseline demographic and clinical assessment administered by trained personnel. Information was collected on age, gender, education, occupational status, living conditions and previous medical conditions. Current smoking status, alcohol intake and physical activity (defined as at least $30 \mathrm{~min}$ of physical activity on at least 3 days per week) were also recorded. Functional status in terms of disability was measured by means of the IADL scale. ${ }^{17}$ This is a scale developed to monitor function and independent living among older adults and measures a broad set of daily activities including shopping for personal items, preparing meals, performing housework and managing personal finances. The Mini-Mental State Examination (MMSE) was used to assess cognition. ${ }^{22}$ To increase reliability, investigators were issued with a specifically designed handbook that contained guidelines for applying tools. A test of the interrater, intercentre reliability of IADL scoring showed good agreement in ratings of each scale item ( $K$ statistic ranging from 0.69 to 0.85$).{ }^{23}$ Participants were re-evaluated on all scales at 1 , 2 and 3 years. Transition to disability was defined as the change from none or one to at least two impaired IADL items.

\section{Statistical analysis}

Data were collected in each centre and entered into a central electronic database on a specifically developed website (www. unifi.it/LADIS). As GDS, MMSE, WMC and progression of WMC were not normally distributed, we used non-parametric statistics - Spearman correlation coefficient and Mann-Whitney tests for the initial analysis. Binary categorical variables were analysed using Fisher's exact test. A binary logistic regression was used to examine further the relationship between progression of WMC and depression at 3 years with covariates of possible confounding variables of age, gender, baseline WMC, MMSE, transition to disability, baseline depression and study centre. The significance level was set at $P<0.05$.

\section{Results}

Magnetic resonance repeat data were obtained from 394 participants. Table 1 shows the characteristics of participants with $v$. without repeat imaging. Those with imaging were on average 2 years younger, had a smaller volume of WMC, higher MMSE and lower GDS scores. The GDS score did not change on average over the 3 years in either group.

Those who had a stroke during the study period had a higher GDS score at 3 years compared with those who did not (4.7 (s.d.=3.3) v. 3.0 (s.d.=2.9), Mann-Whitney $Z=-3.0$, $P=0.002)$. There was, however, no difference in depression incidence at 3 years $(7 / 33 v$. 40/355, Fisher $P=0.10)$ or over the 3 -year study duration $(11 / 31$ v. 78/336, Fisher $P=0.13)$. There was no significant difference in MMSE decline between those with depression at 3 years (change $\mathrm{MMSE}=-1.3($ s.d. $=3.9)$ ) 
Table 1 Participant characteristics ${ }^{a}$

\begin{tabular}{|c|c|c|c|c|c|c|c|}
\hline & \multirow[b]{2}{*}{ Repeat MRI } & \multirow[b]{2}{*}{ No repeat MRI } & \multicolumn{2}{|c|}{ Total, $n$} & \multicolumn{3}{|c|}{ Test statistics } \\
\hline & & & Repeat MRI & No repeat MRI & $t$ & Mann-Whitney, Z & $P$ \\
\hline Age at baseline, years: mean (s.d.) & $73.6(5.0)$ & $75.4(5.0)$ & 394 & 185 & 3.8 & & $<0.001$ \\
\hline Gender, female/male & 210/184 & 104/81 & 394 & 185 & & & $0.53^{b}$ \\
\hline \multicolumn{8}{|l|}{ Mini-Mental State Examination } \\
\hline Baseline, median (range) & $28(16-30)$ & $27(18-30)$ & 394 & 185 & & -5.5 & $<0.001$ \\
\hline 3 year, median (range) & $28(8-30)$ & $27(7-30)$ & 385 & 38 & & -1.3 & 0.2 \\
\hline Change, mean (s.d.) & $-0.9(3.1)$ & $-2.1(6.2)$ & 385 & 38 & -2.0 & & 0.044 \\
\hline \multicolumn{7}{|c|}{$\begin{array}{l}\text { White matter changes, volume }(\mathrm{ml}): \\
\text { median (range) }\end{array}$} & 0.005 \\
\hline \multicolumn{8}{|l|}{ Geriatric Depression Scale ${ }^{c}$} \\
\hline Baseline, median (range) & $2(0-14)$ & $2.5(0-14)$ & 394 & 185 & & 2.25 & 0.011 \\
\hline 3 year, median (range) & $2(0-14)$ & $2.5(0-13)$ & 387 & 36 & & 1.0 & 0.32 \\
\hline Change, mean (s.d.) & $0.16(2.5)$ & $0.36(2.5)$ & 387 & 36 & 0.5 & & 0.6 \\
\hline History of depression, $n$ (\%) & $100(25)$ & $54(29)$ & 394 & 185 & & & $0.36^{b}$ \\
\hline Depressive episode in year $3, n$ (\%) & $47(12)$ & $10(25)$ & 388 & 40 & & & $0.046^{b}$ \\
\hline Stroke during study, $n(\%)$ & $33(9)$ & $13(28)$ & 389 & 47 & & & $0.001^{b}$ \\
\hline \multicolumn{8}{|c|}{$\begin{array}{l}\text { MRI, magnetic resonance imaging. } \\
\text { a. At } 3 \text { years, there were } 101 \text { participants who had dropped out or died. Of the } 84 \text { who refused or were unsuitable for MRI a full interview was only completed for } 36 \text { participants. } \\
\text { b. Fisher's exact test. } \\
\text { c. For Geriatric Depression Scale the maximum score is } 15 .\end{array}$} \\
\hline
\end{tabular}

compared with those without depression (change MMSE $=-0.82$ $($ s.d. $=2.9)$ ).

As Fig. 1 illustrates, progression of WMC was greater in those with $v$. without a depressive episode during year 3 (Mann-Whitney $Z=3.1, P=0.002$; progression of WMC median $2(\mathrm{IQR}=1: 4) v .1$ $(\mathrm{IQR}=0: 3))$. Progression of WMC was also greater in those with $(2(\mathrm{IQR}=1: 3) v$. without $(1(\mathrm{IQR}=0: 3))$ a depressive episode during years 1,2 and 3 (Mann-Whitney $Z=-2.8, P=0.006$ ). There were no significant differences in progression of WMC between those with $v$. without baseline history of depression $(Z=0.11, P=0.9$; median $2(\mathrm{IQR}=0: 3)$ v. $2(\mathrm{IQR}=0: 3))$.

Table 2 shows univariate correlates of the WMC progression. Greater progression of WMC was associated with greater baseline WMC, age at baseline, decline in MMSE and lower MMSE at 3 years but not baseline. There were no significant correlations between progression of WMC and GDS score at baseline or 3 years. Transition to disability over the 3 years was significantly greater (Fisher's exact $P=0.008$ ) in those reporting a depressive episode during year $3(21 / 47) v$. those not reporting depression $(86 / 341)$

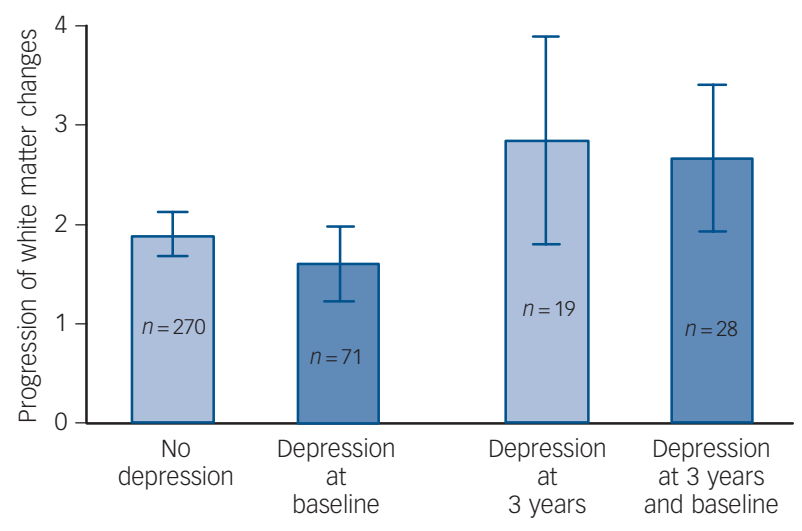

Fig. 1 Mean progression of white matter changes according to baseline history of depression, and depressive incident in year 3 .

Error bars are $95 \%$ confidence intervals.
Table 3 shows the results of a multivariate binary logistic regression of depressive episode during year 3 with variables of age, gender, body mass index, baseline smoking and alcohol status, study centre, baseline MMSE, change in MMSE, incident stroke, baseline WMC volume, baseline history of depression, transition to disability during the study period and progression of WMC. This found that significant predictors of depression at 3 years were baseline history of depression, progression of WMC, baseline alcohol intake and transition to disability.

Table 4 shows the results of a multivariate binary logistic regression, with depressive incident during years $1-3$, with the same covariates. In this model, significant predictors of depressive incident were history of depression, transition to disability, baseline alcohol intake and study centre.

\section{Discussion}

\section{Main findings}

The key finding from this study was that progression of WMC over 3 years predicted incidence of depression at 3 years, even after controlling for baseline WMC, previous history of depression and transition to disability over the 3 years. The data are in line with previous cross-sectional studies showing increased load of WMC in late-onset depression ${ }^{24}$ and support the vascular hypothesis ${ }^{25}$ that vascular disease changes to the brain predispose individuals to the development of depression by disrupting fibre tracts. Although incident depression over all 3 years was associated in a univariate fashion with WMC progression, it was not significant in the multivariate model. This suggests that progression of WMC over the 3 years was more strongly associated with depression at 3 years than during the 3 -year period, and fits with our hypothesis that the WMC precede the depression.

Importantly, we did not find an association between baseline depression and longitudinal increase in WMC. This is in keeping with the findings of the PROSPER study ${ }^{14}$ and with crosssectional studies that found no increase in WMC in older participants with early-onset depression. ${ }^{24}$ Hence, our findings suggest that WMC cause late-life depression rather than vice versa. However, our results are in contrast to those of $3 \mathrm{C}$-Dijon study ${ }^{7}$ that reported a relationship between baseline depression and 


\begin{tabular}{|lccc|}
\hline Table 2 Univariate correlations of progression of white matter changes & & Spearman, rho & $P$ \\
\hline Variable & $n$ & 0.12 & 0.019 \\
\hline Age at baseline & 394 & -0.05 & 0.34 \\
\hline Gender & 394 & 0.48 & 0.001 \\
\hline White matter changes, volume & 387 & 0.01 & 0.84 \\
\hline Baseline Mini-Mental State Examination & 394 & 0.05 & 0.37 \\
\hline Baseline Geriatric Depression Scale & 394 & -0.12 & 0.015 \\
\hline 3-year Mini-Mental State Examination & 385 & 0.06 & 0.26 \\
\hline 3-year Geriatric Depression Scale & 387 & 0.02 & 0.001 \\
\hline 3-year change in Geriatric Depression Scale & 387 & -0.17 & 0.38 \\
\hline 3-year change in Mini-Mental State Examination & 385 & -0.04 & 0.08 \\
\hline Body mass index & 394 & 0.09 & 0.21 \\
\hline Smoker at baseline & 394 & 0.09 & 0.96 \\
\hline Alcohol at baseline, g/day & 205 & 0.00 & \\
\hline Physical activity at baseline, yes/no & 394 & & \\
\hline
\end{tabular}

\begin{tabular}{|lccc|}
\hline Table 3 Binary logistic regression of depressive episode during year $3(n=23 / 198)$ & $P$ & Hazard ratio $(95 \%$ Cl) \\
\hline Age & Wald & 0.31 & $0.94(0.82-1.07)$ \\
\hline Female & 1.03 & 0.94 & $1.06(0.23-4.83)$ \\
\hline Baseline WMC, volume & 0.01 & 0.60 & $0.82(0.38-1.74)$ \\
\hline Transition to disability & 0.28 & 0.011 & $8.43(1.57-45.35)$ \\
\hline History of depression at baseline & 6.42 & 0.009 & $7.61(1.62-35.76)$ \\
\hline Incident stroke & 6.88 & 0.10 & $4.50(0.72-28.09)$ \\
\hline MMSE baseline & 2.70 & $0.87(0.66-1.14)$ \\
\hline 3-year change in MMSE & 1.03 & $1.01(0.83-1.24)$ \\
\hline Body mass index baseline & 0.01 & 0.92 & $1.01(0.84-1.22)$ \\
\hline Physical activity & 0.01 & 0.91 & $1.17(0.18-7.83)$ \\
\hline Smoking baseline & 0.03 & 0.13 & $(0.01-1.43)$ \\
\hline Alcohol baseline, g/day & 2.89 & 0.089 & $1.05(1.01-1.09)$ \\
\hline Progression of WMC ${ }^{2}$ & 5.99 & 0.014 & $1.41(1.00-2.00)$ \\
\hline Study centre & 3.90 & 0.048 & \\
\hline $\begin{array}{l}\text { WMC, white matter changes; MMSE, Mini-Mental State Examination. } \\
\text { a. Progression of WMC using the Rotterdam Progression scale. }\end{array}$ & 11.69 & 0.23 & \\
\hline
\end{tabular}

\begin{tabular}{|lccc|}
\hline Table 4 Binary logistic regression of depressive episode during year $1+2+3(n=41 / 188)$ & Hazard ratio (95\% Cl) \\
\hline Age & Wald & $P$ & $1.04(0.95-1.15)$ \\
\hline Female & 0.71 & 0.40 & $1.12(0.36-3.53)$ \\
\hline Baseline WMC, volume & 0.04 & 0.84 & $1.14(0.66-1.97)$ \\
\hline Transition to disability & 0.22 & 0.64 & $5.14(1.42-18.6)$ \\
\hline History of depression at baseline & 6.47 & 0.011 & $8.12(2.71-24.3)$ \\
\hline Incident stroke & 14.58 & $<0.001$ & $1.50(0.30-7.57)$ \\
\hline MMSE baseline & 0.26 & 0.61 & $0.89(0.70-1.13)$ \\
\hline 3-year change in MMSE & 0.96 & 0.33 & $0.96(0.80-1.14)$ \\
\hline Body mass index baseline & 0.26 & 0.61 & $1.08(0.93-1.25)$ \\
\hline Physical activity & 1.01 & $0.82(0.22-3.06)$ \\
\hline Smoking baseline & 0.09 & 0.31 & $1.03(0.09-2.49)$ \\
\hline Alcohol baseline, g/day & 0.84 & 0.77 & $0.90-1.06)$ \\
\hline Progression of WMC ${ }^{a}$ & 4.73 & 0.36 & $0.74-1.34)$ \\
\hline Study centre & 0.00 & 0.030 & 0.97 \\
\hline WMC, white matter changes; MMSE, Mini-Mental State Examination. & 20.09 & 0.017 & \\
\hline a. Progression of WMC using the Rotterdam Progression scale. & & & \\
\hline
\end{tabular}


WMC progression. The demographics of the study populations may underlie the differences. Unlike the electoral roll-based Dijon study, our study was of non-disabled community dwellers who were selected as they already had WMC. In keeping with other studies, ${ }^{26}$ we found baseline WMC a strong predictor of WMC progression. Hence pre-existing vascular disease is likely to be a major cause of WMC progression in our study.

Our findings of progression of WMC predicting future episodes of depression are contrary to the longitudinal PROSPER study. ${ }^{14}$ Again, the discrepancy may be due to differences in the cohorts studied. The PROSPER study had much lower WMC load $(2 \mathrm{ml} v$. our $15 \mathrm{ml})$ and had lower incidence of depression, and hence the WMC burden may not have been sufficient to detect an increase in the incidence of depressive features. Our results are, however, in line with a study of older participants with depression at baseline, ${ }^{11}$ in which poorer outcome of depression was associated with progression of WMC, but not baseline levels of WMC.

We did not find a relationship between WMC progression and depressive symptoms as measured by the self-reported GDS. Since our definition of incident depression was that the participant received treatment, it is possible that effective treatment for depressive symptoms may have reduced GDS scores when they were recorded. Alternatively, those with worse depressive symptoms at the time of follow-up may have been more likely to decline participation.

There was a significant effect of study centre on depression over 3 years. Since the centres were heterogeneous in terms of their clinical focus (neurology, psychiatry, stroke clinics, etc.) and also culturally due to the pan-European nature of the LADIS study, it seems possible that this effect was as a result of the differing nature of the recruited population at each centre. Alcohol use at baseline was associated with depressive incidents during the study. The associations between alcohol and depression are bidirectional, with alcohol often being used by people with depression, but also leading to the development of depression. ${ }^{27}$

We have demonstrated a significant association between progression of WMC over 3 years, and depression at 3 years, controlling for a number of confounding variables. However, it is difficult to unambiguously identify a direct causal relationship between WMC and depression, because of the interlinking relationships between cardiovascular disease, disability, cognitive problems and depression. For example there are established associations between WMC and both cognitive decline ${ }^{28}$ and reduced daily physical functioning, ${ }^{29}$ and both of these in turn have links to depressive features.

\section{Strengths and limitations}

Limitations of the study are the use of a rating scale to assess WMC progression, rather than volumetric analysis, although the Rotterdam Progression scale has been widely used and is reliable and sensitive to change. ${ }^{30}$ We chose to use this scale for measuring progression, since we were not aware of any volumetric methods that had been validated in a multicentre setting, and we were concerned that the volumetric measurement might be too dependent on the MRI sequence used at the different locations. There was some participant attrition over the study period that may have affected the results, but our attrition rate is not uncommon for studies of this size and duration in older people. Arguably, those who developed depression would have been more likely to drop out, and thus if anything, the attrition rate possibly tended to reduce the significance of our findings.

Our measurement of incident depression was a depressive episode that had resulted in treatment or admission to hospital.
Thus, we may have missed some cases in which the participant did not seek treatment for their illness. There may also have been lack of specificity in the diagnosis, as we did not use a standard procedure for depression (for example DSM-IV ${ }^{31}$ ). However, the advantage of our approach is that it should capture incidents of depression occurring at any point over the study period, rather than just at the time of assessment.

The strengths of the study are the large, multicentre, panEuropean design and the size of the population, all of which increase the generalisability of the findings. We used a standardised imaging protocol, and obtained repeat imaging using the same protocol at 3 years. Analysis of scans was centralised and undertaken masked to all clinical outcome data. Unlike other studies, our comprehensive assessment package allowed us to investigate key potential confounds, such as the development of disability and cognitive impairment, which might possibly mediate the relationship between progression of WMC and future depression.

\section{Implications}

In conclusion, we found evidence that progression of WMC is associated with incidence of depression, even when controlling for other factors. Our previous reports have found an association between WMC at baseline and future depression, and we found no evidence of the reverse association between depression at baseline and future progression of WMC. Our results therefore support the vascular hypothesis of depression and are consistent with WMC pre-dating and playing a key aetiological role in the development of depression in older people. Trials of antihypertensive drugs have demonstrated that successful blood pressure control reduces progression of WMC. ${ }^{32,33}$ Reducing white matter lesion progression by means of control of vascular risk factors should thus be investigated as a potentially important strategy in treating older people with, or at risk of, depression. and Health, Newcastle University, Newcastle, UK; Wiesje M. van der Flier, PhD, Alida A. Gouw, MD, Department of Radiology and Neurology, VU Medical Center, Amsterdam, The Netherlands; Anders Wallin, MD, PhD, Institute of Clinical Neuroscience, Göteborg University, Göteborg, Sweden; Timo Erkinjuntti, MD, PhD, Memory Research Unit, Department of Clinical Neurosciences, Helsinki University, Helsinki, Finland; Domenico Inzitari, MD, Department of Neurological and Psychiatric Sciences, University of Florence, Florence, Italy; Lars-Olof Wahlund, MD Psychiatric Sciences, University of Florence, Florence, Italy; Lars-Olof Wahlund, MD,
PhD, Karolinska Institutet, Department of Neurbiology, Care Sciences and Society and Karolinska University Hospital, Huddinge, Sweden; Leonardo Pantoni, MD, PhD, Anna Poggesi, MD, Giovanni Pracucci, MD, Department of Neurological and Psychiatric Sciences, University of Florence, Florence, Italy; Peter Langhorne, MD, BSC, PhD, FRCP, John T. O'Brien, DM, Institute for Ageing and Health, Newcastle University, Newcastle, UK

Correspondence: Michael Firbank, PhD, Institute for Ageing and Health, Newcastle University Wolfson Research Centre, Campus for Ageing and Vitality, Newcastle upon Tyne NE4 5PL, UK. Email: michael.firbank@ncl.ac.uk

First received 1 Jul 2011, final revision 6 Feb 2012, accepted 15 Mar 2012

\section{Funding}

The LADIS study is supported by the European Union within the V European Framework Programme 'Quality of life and management of living resources' (1998-2002), contract no: QLRT-2000-00446 as a concerted action. This work was supported by the UK NIHR Biomedical Research Centre for Ageing and Age Related Diseases award to the Newcastle upon Tyne Hospitals NHS Foundation Trust.

\section{Acknowledgements}

A list of participating centres and personnel can be found in the online supplement. 


\section{References}

1 Debette S, Seshadri S, Beiser A, Au R, Himali JJ, Palumbo C, et al. Midlife vascular risk factor exposure accelerates structural brain aging and cognitive decline. Neurology 2011; 77: 461-8.

2 Godin O, Tzourio C, Maillard P, Mazoyer B, Dufouil C. Antihypertensive treatment and change in blood pressure are associated with the progression of white matter lesion volumes: the three-city (3D)-Dijon magnetic resonance imaging study. Circulation 2008; 123: 266-73.

3 van Dijk EJ, Prins ND, Vrooman HA, Hofman A, Koudstaal PJ, Breteler MMB. Progression of cerebral small vessel disease in relation to risk factors and cognitive consequences: Rotterdam scan study. Stroke 2008; 39: 2712-9.

4 de Groot JC, de Leeuw FE, Oudkerk M, Hofman A, Jolles J, Breteler MMB. Cerebral white matter lesions and depressive symptoms in elderly adults. Arch Gen Psychiatry 2000; 57: 1071-6.

5 O'Brien J, Desmond P, Ames D, Schweitzer I, Harrigan S, Tress B. A magnetic resonance imaging study of white matter lesions in depression and Alzheimer's disease. Br J Psychiatry 1996; 168: 477-85.

6 O'Brien JT, Firbank MJ, Krishnan MS, van Straaten ECW, van der Flier WM, Petrovic $\mathrm{K}$, et al. White matter hyperintensities rather than lacunar infarcts are associated with depressive symptoms in older people: the LADIS study Am J Geriatr Psychiatry 2006; 14: 834-41.

7 Godin O, Dufouil C, Maillard P, Delcroix N, Mazoyer B, Crivello F, et al. White matter lesions as a predictor of depression in the elderly: the 3C-Dijon study. Biol Psychiatry 2008; 63: 663-9.

8 Teodorczuk A, O'Brien JT, Firbank MJ, Pantoni L, Poggesi A, Erkinjuntti T, et al. White matter changes and late-life depressive symptoms. Longitudinal study. Br J Psychiatry 2007; 191: 212-7.

9 O'Brien J, Ames D, Chiu E, Schweitzer I, Desmond P, Tress B. Severe deep white matter lesions and outcome in elderly patients with major depressive disorder: follow up study. BMJ 1998; 317: 982-4.

10 Heiden A, Kettenbach J, Fischer P, Schein B, Ba-Ssalamah A, Frey R, et al. White matter hyperintensities and chronicity of depression. J Psychiatr Res 2005; 39: 285-93.

11 Taylor WD, Steffens DC, MacFall JR, McQuoid DR, Payne ME, Provenzale JM et al. White matter hyperintensity progression and late-life depression outcomes. Arch Gen Psychiatry 2003; 60: 1090-6.

12 Hickie I, Scott E, Wilhelm K, Brodaty H. Subcortical hyperintensities on magnetic resonance imaging in patients with severe depression - a longitudinal evaluation. Biol Psychiatry 1997; 42: 367-74.

13 Thomas AJ, Kalaria RN, O'Brien JT. Depression and vascular disease: what is the relationship? J Affect Disord 2004; 79: 81-95.

14 versluis $C E$, van der Mast, $\mathrm{RC}$, van Buchem MA, Bollen E, Blauw GJ, Eekhof JAH, et al. Progression of cerebral white matter lesions is not associated with development of depressive symptoms in elderly subjects at risk of cardiovascular disease. The PROSPER study. Int J Geriatr Psychiatry 2006; 21: 375-81.

15 Teodorczuk A, Firbank MJ, Pantoni L, Poggesi A, Erkinjuntti T, Wallin A, et al. Relationship between baseline white matter changes and development of late life depressive symptoms: 3 year results from the LADIS study. Psychol Med 2010; 40: 603-10.

16 Pantoni L, Basile AM, Pracucci G, Asplund K, Bogousslavsky J, Chabriat H, et al. Impact of age-related cerebral white matter changes on the transition to disability - the LADIS study: rationale, design and methodology Neuroepidemiology 2005; 24: 51-62.

17 Lawton MP, Brody EM. Assessment of older people: self-maintaining and instrumental activities of daily living. Gerontologist 1969; 9: 179-86.

18 Fazekas F, Chawluk JB, Alavi A, Hurtig HI, Zimmerman RA. MR signal abnormalities at $1.5 \mathrm{~T}$ in Alzheimer's dementia and normal aging. Am $\mathrm{J}$ Neuroradiol 1987; 8: 421-6.

19 Van Straaten EC, Fazekas F, Rostrup E, Scheltens P, Schmidt R, Pantoni L, et al. Impact of white matter hyperintensities scoring method on correlations with clinical data: the LADIS study. Stroke 2006; 37: 836-40.

20 Gouw AA, van der Flier WM, Fazekas F, van Straaten ECW, Pantoni L, Poggesi A, et al. Progression of white matter hyperintensities and incidence of new lacunes over a 3 year period. Stroke 2008; 29: 1414-20.

21 Yesavage JA. Geriatric Depression Scale. Psychopharmacol Bull 1988; 24 709-11.

22 Folstein MF, Folstein SE, McHugh PR. A practical method for grading the cognitive state of patients for the clinician. J Psychiatr Res 1975; 12: 189-98.

23 Inzitari D, Simoni M, Pracucci G, Poggesi A, Basile AM, Chabriat H, et al. Risk of rapid global functional decline in elderly patients with severe cerebral agerelated white matter changes - the LADIS study. Arch Intern Med 2007; 167: 81-8.

24 Herrmann LL, Le Masurier M, Ebmeier KP. White matter hyperintensities in late life depression: a systematic review. J Neurol Neurosurg Psychiatry 2008; 79: 619-24.

25 Alexopoulos GS, Meyers BS, Young RC, Campbell S, Silbersweig D, Charlson M. 'Vascular depression' hypothesis. Arch Gen Psychiatry 1997; 54: 915-22.

26 Schmidt R, Enzinger C, Ropele S, Schmidt H, Fazekas F. Progression of cerebral white matter lesions: 6 year results of the Austrian stroke prevention study. Lancet 2003; 361: 2046-8.

27 Boden JM, Fergusson DM. Alcohol and depression. Addiction 2011; 106 906-14.

28 Verdelho A, Madureira S, Moleiro C, Ferro JM, Santos CO, Erkinjuntti T, et al. White matter changes and diabetes predict cognitive decline in the elderly: the LADIS study. Neurology 2010; 75: 160-7.

29 Inzitari D, Pracucci G, Poggesi A, Carlucci G, Barkhof F, Chabriat H, et al. Changes in white matter as determinant of global functional decline in olde independent outpatients: three year follow-up of LADIS (leukoaraiosis and disability) study cohort. BMJ 2009; 339: b2477.

30 Gouw AA, van der Flier WM, van Straaten ECW, Pantoni L, Bastos-Leite AJ Inzitari D, et al. Reliability and sensitivity of visual scales versus volumetry for evaluating white matter hyperintensity progression. Cerebrovasc Dis 2008; 25: $247-53$

31 American Psychiatric Association. Diagnostic and Statistical Manual of Mental Disorders (4th edn) (DSM-IV). APA, 1994.

32 Dufouil C, Chalmers J, Coskun O, Besançon V, Bousser M-G, Guillon P, et al. Effects of blood pressure lowering on cerebral white matter hyperintensities in patients with stroke: the PROGRESS (Peridopril Protection Against Recurrent Stroke Study) magnetic resonance imaging substudy. Circulation 2005; 112: 1644-50

33 Firbank MJ, Wiseman RM, Burton EJ, Saxby BK, O'Brien JT, Ford GA. Brain atrophy and white matter hyperintensity change in older adults and relationship to blood pressure. J Neurol 2007; 254: 713-21. 